\title{
ESCRITURA, MEMÓRIA E MORTE SÔBOLOS RIOS
}

\author{
Cid Ottoni Bylaardt \\ (Universidade Federal do Ceará)
}

\section{RESUMO}

O romance Sôbolos rios que vão, de António Lobo Antunes parece ser um texto memorialístico em forma de diário. Entretanto, a escritura é tão fragmentada, dispersa e hesitante que as imagens, os fatos, as personagens e as vozes vão se acumulando como se estivessem a buscar algo que não encontram, configurando um trânsito textual entre o diário e a dispersão romanesca. Assim, a escritura de Lobo Antunes aqui se faz linguagem poética presidida por duas grandes imagens: a da água e a da morte. Essas duas imagens predominantes no romance constituem o objeto deste ensaio, que discute suas relações com a indeterminação da escritura do romancista português. Temos aí portanto Sôbolos rios que vão, um diário que não é diário, um texto vacilante e irresoluto como a voz narrativa anônima que parece conduzi-lo, misturada a outras vozes e outras pessoas, como as águas que rolam, banhando o papel em que se escreve.

PALAVRAS-CHAVE: romance português contemporâneo, António Lobo Antunes, água e morte na escritura.

\section{ABSTRACT}

The novel Sôbolos rios que vão (Over the rivers that flow), by António Lobo Antunes, seems to be a memorialistic text built like a diary. Nevertheless, the writing is so fragmented, disperse and hesitating that the images, the facts, the characters and the voices intermingle, as if they were seeking something they never find, configuring thus a textual passage from the diary to the novelistic dispersion. Lobo Antunes' writing, therefore, turns out to be true poetic language, presided over by two great images: death and water. These two prevailing images are the subject of this paper, which discusses its relations with the indeterminacy of the portuguese novelist's writing. So we have Sôbolos rios que vão, a diary that is not a diary, a vacillating and irresolute text like the anonimous narrative voice that seems to lead it, mixed to other voices and persons, like the waters that flow, bathing the paper in which it is written.

KEYWORDS: Portuguese Contemporary Literature, António Lobo Antunes, water and death in writing. 
Sôbolos rios que vão (2010), vigésimo-segundo romance de António Lobo Antunes, é uma narrativa cujos eventos giram em torno da memória de um doente de câncer que se encontra em um quarto de hospital em Lisboa, um certo senhor Antunes, ou Antoninho. $\mathrm{O}$ enunciado está compreendido entre os dias 21 de março e 4 de abril de 2007, totalizando quinze capítulos, cada um deles tendo uma data como título, o que dá ao texto ares de um diário. Considerando que o autor teve um câncer diagnosticado no primeiro semestre de 2007, do qual hoje é dado como curado, não faltam os que pretendem descobrir triunfantemente elementos autobiográficos na narrativa, a estabelecer uma identidade duvidosa entre autor, narrador e personagem, o que nos parece uma atitude tão irrelevante quanto inconsistente, por mais que o nome esteja lá, a denunciar uma pretensa identidade.

A voz predominante é de um narrador anônimo de terceira pessoa, fato que dificulta classificar a narrativa como um diário, no sentido tradicional do gênero, e que a afasta do discutível "pacto autobiográfico" de Philippe Lejeune, o que preserva a constatação de que as narrativas de Antunes são inclassificáveis. Embora exista um locutor de terceira pessoa, o que se espera desse autor singular, e isso de fato ocorre, é que não haja um enunciador onipotente, condutor, a guiar a escritura por um caminho diegético seguro, lembrando o deslocamento identitário preconizado por Rimbaud na expressão “je est un autre”. Assim, a locução do próprio doente se intromete na fala anônima, bem como a do avô, às vezes a de um enfermeiro, e mais alguns outros personagens. Por outro lado, a predominância da voz narrativa anônima não impede que ela seja hesitante, alinear, irresoluta. Lobo Antunes, aliás, já escreveu um outro romance, Não entres tão depressa nesta noite escura, em que o texto parece ser o diário da personagem Maria Clara, e formalmente o texto tem mais semelhanças com o gênero confessional. Todavia, a "autora" também cria uma escrita fragmentária, em que os fatos não se determinam, onde irrompem outras vozes e acontecimentos, configurando a incompletude e a dispersão da narrativa. Ao final, a "autobiógrafa" tenta dar um desfecho ao relato, mas o que há é mais uma desistência do que uma conclusão, e a escrita permanece suspensa.

Sobre os gêneros confessionais, um dos textos mais curiosos de Léspace littéraire é aquele que Blanchot intitula "Recours au jornal". O autor afirma que certos escritores mantêm um diário para que possam conservar uma relação consigo mesmos, para que o ser que se recusa a renunciar a si próprio volte-se para aquele que realmente é, quando não escreve, "quand il vit la vie quotidienne, quand il est vivant et vrai, et non pas mourant et sans vérité"' (BLANCHOT, 1999, p. 24). Sabe-se que Lobo Antunes mantém 
seus diários, suas crônicas, que ele publica periodicamente. Sabe-se também que muitos dos elementos registrados em suas crônicas terminam por virar trechos de romances. Entretanto, o texto que aqui se apresenta não se assemelha ao gênero diário mencionado por Blanchot, e muito menos às crônicas que Lobo Antunes escreve regularmente, em que ele descreve fatos, faz reflexões pessoais, dá conselhos, fala sobre a vida de escritor.

Outro aspecto que chama a atenção de imediato é o título, uma apropriação do primeiro verso das Redondilhas de Babel e Sião de Camões, por sua vez inspiradas no salmo 136, "Junto aos rios de Babilônia", Livro de salmos do Antigo Testamento, em que David narra o exílio dos hebreus cativos em Babilônia. No poema de Camões, um enunciador em primeira pessoa constrói as alegrias de seu passado em Sião em confronto com o sofrimento do presente em Babilônia.

Embora o assunto, o gênero, a forma, a linguagem do poema e do romance sejam completamente diferentes, podem-se estabelecer algumas aproximações entre os dois, principalmente em algumas concepções de escritura e memória que o locutor camoniano emite e que a narrativa de Lobo Antunes desdobra e transforma. Ao declarar, por exemplo, que "Bem são rios estas águas,/ com que banho este papel” (CAMÕES, 2005. p. 106, vv. 51 e 52), o enunciador de Camões alude a uma figuração que pode ser considerada essencial no texto antuniano: a de que a escritura é levada e lavada pelas águas irreprimidas do rio, compondo um entrelaçamento confuso entre presente e passado, a delinear pela linguagem um sofrimento multifacetado. Também os versos 211 a 216 seguintes aludem à construção da memória, determinante da escritura do romance:
Mas ó tu, terra de Glória, se eu nunca vi tua essência como me lembras na ausência? Não me lembras na memória, senão na reminiscência.

(CAMÕES, 2005, p. 109)

Os versos sugerem que não há memória, há reminiscência, e a própria recordação é problematizada pelo fato de que quem lembra não conhece a essência da coisa lembrada. Temos, assim, uma verdade imemorial, que não é construída como resgate, mas como invenção.

Tanto o título do romance, que raras vezes em Lobo Antunes apresenta, como aqui, uma relação direta com a matéria narrada, quanto as reminiscências de águas que banham o papel em que se escreve desembocam de maneira incontornável na ideia do rio, ou dos rios, relacionada à escritura e à memória. $\mathrm{O}$ rio Mondego é presença constante nas memórias do personagem, sob várias figurações. Uma delas, que aparece com certa insistência, é a da nascente do rio, que o pai lhe mostrara em algum momento do passado e que parece ser o início de um caminho a se percorrer sobre os rios da escritura, inicialmente como tentativa vã de buscar esse ponto ini- 
cial, "um fiozito entre penedos quase no alto da serra" (ANTUNES, 2010, p. 16), a nascente da própria lembrança, um "fiozito", nada mais.

Essa busca insistente da nascente do Mondego força uma reflexão sobre o andamento originário da linguagem poética, sua fala singular, inabitual, aquilo que não se desgastou, que preserva o encanto da descoberta, como tenta dizer a poesia de Manoel de Barros, que se inclui entre as leituras de Lobo Antunes. Em seu artigo "Sôbolos Rios Que Vão de António Lobo Antunes: quando as semelhanças não podem ser coincidências", Ana Paula Arnaut menciona o desejo do escritor de "reduzir a escrita ao osso, assim prosseguindo a sua obsessão de escrever um livro onde o silêncio seja completo" (ARNAUT, 2011, p. 1). Sobre o silêncio em Lobo Antunes, falaremos mais adiante; por ora, o osso.

Quanto à ideia do osso, Manoel de Barros tem um poema curioso, chamado "Escova", à frente transcrito:

Eu tinha vontade de fazer como os dois homens que vi sentados escovando osso. No começo achei que aqueles homens não batiam bem. Porque ficavam sentados na terra o dia inteiro escovando osso. Depois aprendi que aqueles homens eram arqueólogos. E que eles faziam o serviço de escovar osso por amor. E que eles queriam encontrar nos ossos algum vestígio de antigas civilizações que estariam enterradas por séculos naquele chão. Logo pensei de escovar palavras. Porque eu havia lido em algum lugar que palavras eram conchas de clamores antigos. Eu queria ir atrás dos clamores antigos que estariam guardados dentro das palavras. Eu já sabia também que as palavras possuem no corpo muitas oralidades remontadas e muitas significâncias remontadas. Eu queria então escovar as palavras para escutar o primeiro esgar de cada uma. Para escutar os primeiros sons, mesmo que ainda bígrafos. Comecei a fazer isso sentado em minha escrivaninha. Passava horas inteiras, dias inteiros fechado no quarto, trancado a escovar palavras. Logo a turma perguntou: o que eu fazia o dia inteiro trancado naquele quarto? Eu respondi a eles, meio entressonhado, que eu estava escovando palavras. Eles acharam que eu não batia bem. Então eu joguei a escova fora. (BARROS, 2003, folheto I)

Essa busca das "significâncias remontadas" parece ter muito a ver com a nascente do Mondego na narrativa poética de Lobo Antunes. Bianca Albuquerque define assim a atitude do poeta:

Ao escovar vocábulos, esse sujeito pretende libertar os estereótipos das palavras, ou seja, afastar os significados que nelas se incrustaram ao longo do tempo e as endureceram, visando a permitir um uso mais abrangente e menos restrito a determinadas convenções da língua (COSTA, 2011, p. 44). 
Bianca continua suas reflexões lembrando Roland Barthes, em Leçon, e sua ideia de estereótipo, segundo o pensador francês um monstro que dorme dentro de cada signo, que recolhe aquilo que se arrasta na língua. Esse movimento em direção a sua nascente é a tentativa de se libertar da carga de estereótipos que a linguagem carrega. Nascente, origem, osso: os termos não querem ser precisos, possivelmente porque não querem estabelecer-se, condenarem-se à verdade. Talvez seja essa a essência da arte, da poesia: buscar essa verdade originária que nenhum conceito metafísico poderá definir, a busca do momento não contaminado em que a linguagem está diante do artista para se fazer poesia. É uma ideia cara a Heidegger, a Blanchot, a Foucault, a Barthes, a Agamben, enfim, a muitos dos que pensam a literatura, dos que refletem sobre a poesia.

A linguagem poética não é uma língua como sistema. Consoante Agamben, Dante procurava, no De Vulgari eloquentia, "aquele vulgar ilustre que, deixando em todas o seu perfume, não se confundia com nenhuma" (AGAMBEN, 1999, p. 40). Enquanto o ser apenas compartilha a língua materna, a língua comum, que divide com os demais, ele participa de um sistema. Por mais que tenha a ilusão de dizer verdades, ele só diz alguma coisa, nem verdade nem metalinguagem. No momento em que se depara com a palavra única, é inevitável tomar partido, ou não se pode ser poeta. E essa língua não tem uma destinação, essa língua não tem identidade, porque o poeta se coloca diante do vazio das palavras. Ele é então uma criança diante do que se expõe a ela. É o infante, do latim infans, antis, o que não fala, e portanto não tem o que dizer dela e sobre ela, por mais que ela acene com a promessa de produzir um sentido, de estabelecer um destino, sustentada em sua gramática, em sua tradição. O poeta é, então, esse infante que se coloca diante dessa vanidade, desse oco, desse vazio, mas não sabe como preenchê-lo, talvez não saiba nunca. Daí nasce a poesia.

A nascente, a perplexidade do escritor-criança diante da carga das palavras, e sua tentativa de escová-las, todavia, não pode ser verdadeiramente encontrada, e a narrativa segue sôbolos rios. O avô do personagem hospitalizado lhe deseja que repouse e que embarque na memória do sonho: "talvez sonhes com a nascente do Mondego e caminhes juntamente com o rio numa névoa de luz" (ANTUNES, 2010, p. 20). Não se pode deixar de relacionar esse caminhar com o rio à escritura, e assim são frequentes as referências à descida do Mondego, rio que ganha força em seu deslizar no sentido da foz, mas um deslizar trôpego, indiscernível como a memória, "difícil de distinguir no nevoeiro do Mondego" (ANTUNES, 2010, p. 26), inelutável como seu clamor pela vida, e evidentemente pela escritura - "levem-me com vocês a caminhar sobre os rios" (ANTUNES, 2010 , p. 65) -, ou confiante como sua declaração à mãe: "vou com os rios mãe" (ANTUNES, 2010, p. 82), e assim julgava que "descia sobre os rios a caminho do mar", ele que já sabia o que precisava saber, independentemente do que o pai podia lhe ensinar - "bastava a certeza de chegar à foz" (ANTUNES, 2010, p. 83). 
Ao mesmo tempo, a nascente não é algo que se processa e se estabelece como ato de vir à luz e acontecer: "a humidade feita de líquenes do Mondego que não termina de nascer numa falha de penhascos" (ANTUNES, 2010, p. 32). Tanto nascer quanto morrer pertencem a um contínuo incessante: jamais se morre completamente, como nunca se nasce em definitivo.

A narrativa de Lobo Antunes lida basicamente com duas imagens: a da água e a da morte. Mas o que é propriamente a imagem? Benedetto Croce, em seu Breviário de estética, ao apresentar a arte como intuição, relaciona-a ao mundo das imagens, destituídas de função moral, hedonística, filosófica, histórica, religiosa ou científica. O discurso de Croce nos autoriza a concluir que a arte não é feita de um acúmulo de imagens, mas é constituída por um princípio vital, um organismo, que ele chama intuição-imagem (CROCE, 2008, p. 26). Para Blanchot, um poema não é um poema por utilizar um certo número de imagens (metáforas, símiles etc.), mas é em si uma imagem, imagem de linguagem:

Il faut donc exprimer d'autrement ce que nous cherchons: est-ce que le langage lui-même ne devient pas, dans la littérature, tout entière image, non pas un langage qui contiendrait des images ou qui mettrait la realité en figures, mais qui serait sa propre image, image de langage, - et non pas une langage imagé ou encore langage imaginaire, langage que personne ne parle, c'est-à-dire qui se parle à partir de sa propre absence, comme l'image apparait sur l'absence de la chose, langage qui s'addresse aussi à l'ombre des événements, non à leur réalité, et par ce fait que les mots qui les expriment ne sont pas des signes, mais des images, images des mots et mots où les choses se font images. ${ }^{2}$ (BLANCHOT, 1999, p. 32)

A ideia blanchotiana de imagem está associada à experiência da morte e de seus despojos. O cadáver torna-se mais grandioso, mais admirável do que o humano vivo; ele é, portanto, a imagem de si mesmo (e não da pessoa que foi). Ao perder seu valor de uso e de verdade, o cadáver adquire uma existência neutra em sua relação com o mundo, que na verdade não se assemelha a nada. O próprio homem, quando vivo, assemelha-se pouco a si mesmo, uma vez que em vida ele era mais uma função do que um ser; ao tornar-se cadáver, o ser perde a utilidade, tornando-se pura imagem de nada, o neutro que será depositado na impessoalidade do cemitério. $\mathrm{O}$ texto literário, em sua fabulação da impossibilidade, toma para si o caráter incomum e neutro da imagem cadavérica.

O que Maurice Blanchot chama "semelhança cadavérica" pode-se relacionar à possibilidade ensejada pela escritura no mundo: o morto lembra o vivo querido, mas essa semelhança é magnificada, e essa imagem soberba erige a verdade da morte na linguagem do engrandecimento. 
Eis o outro lado do processo imagístico. O morto torna-se a imagem de si mesmo, sombra e apagamento diante do objeto em que inicialmente se refletia, a partir do processo de desfuncionalização do morto. Agora ele é semelhante a nada, um ser sem verdade.

O utensílio cuja obsolescência lhe retira o valor de uso aparece independentemente de sua utilidade. A semelhança cadavérica eleva-se, assim, à condição de arte:

La catégorie de l'art est liée à cette possibilité pour les objects d'“apparaître", c'est-à-dire de s'abandonner à la pure et simple resemblance derrière laquelle il n'y a rien - que l'être. N'apparaît que ce qui s'est livré à l'image, et tout ce qui apparaît est, en ce sens, imaginaire. ${ }^{3}$ (BLANCHOT, 1999, p. 348)

Estamos na região do inacessível, onde não há repouso. A morte, com toda sua verdade construída no mundo, não consegue manter-se no belo lugar que lhe reservaram. O defunto da arte anda sem destino. Nesse caso, a semelhança move-se para substituir o real, a identidade parece ser "constituída" pela semelhança e suas qualidades, sem ser nem qualidade nem semelhança.

Para Levinas, ser-o-que-é, o real em sua verdade, já está no imaginário. $\mathrm{O}$ estar-no-imaginário do real é uma espécie de exotismo originário, é a estrutura do sensível como tal. O caráter sensível da coisa, suas qualidades (vermelho, duro, sonoro, aromático) fazem-na imaginável, e ser imaginável nada mais é do que a verdade da coisa. O que é perdido, a presa que a arte deixa escapar, desdobra-se no próprio evento do imaginário, um evento que não pode ser imaginado (mas sentido), um evento no qual o real já está envolvido.

A arte insiste na ausência do objeto, que não é o ponto de partida do sensível. Consoante Levinas, fulgurações de cores, fragmentos de matéria estranha, sons, palavras que dizem sem dizer "occupent entièrement sa place pour marquer son éloignement comme si l'object représenté mourait, se dégradait, se désincarnait dans son propre reflet"4 (LEVINAS, 2008, p. 116). A arte não reflete simplesmente essa evasão; completa-a, põe-na para fora, intensifica-a, como se a realidade da coisa não contasse para nada. $\mathrm{Na}$ medida em que faz isso, introduz no mundo a atmosfera do intervalo temporal que Levinas chama l'entretemps. Como imagem, a obra de arte será sempre fixada en l'entretemps. Essa fixidez é diferente do conceito, que atrai a vida, que oferece a realidade aos nossos poderes, à verdade, propicia uma dialética. Por seu reflexo na narrativa, o ser tem uma fixidez não-dialética, faz parar a dialética e o tempo. A arte, portanto, substitui o conceito pela imagem. $\mathrm{O}$ artista não se interessa pela inteligibilidade do objeto, não almeja conhecê-lo, atribuir-lhe uma função ou uma tarefa. Essa atitude afasta-o de toda direcionalidade, de toda intencionalidade consciente. 
Essa passividade radical provoca a suspensão, o entretemps. A Mona Lisa anuncia o desabrochar de seu sorriso, que desabrochará eternamente sem jamais desabrochar, eis a suspensão. No gênero narrativo, a fixidez da imagem no entretemps não é abalada. Os personagens de um romance são seres prisioneiros, sua história nunca termina, ela dura sempre, e nunca avança. $\mathrm{O}$ nosso Antoninho, ou senhor Antunes, segue um curso sem seguir, ao sabor dos rios, das águas, da morte, como o paradoxo da flecha, de Zenão de Eleia: se a flecha em voo sempre ocupa espaço igual às suas próprias dimensões, logo a flecha em voo está em repouso.

O real é vulnerável ao tempo, a imagem da finitude marca sua vida, que só é vida porque tem direito à morte, o ser para a morte de Heidegger. Na arte, na imagem, o tempo de morrer se processa de outra forma, não mais como um corte no contínuo do tempo:

Le temps-même du "mourir" ne peut pas se donner l'autre rive. Ce que cet instante a d'unique et de poignant tient au fait de ne pas pouvoir passer. Dans le "mourir", l'horizont de l'avenir est donnée, mais l'1avenir en tant que promesse du present nouveau est refusé - on est dans l'intervalle, à jamais intervalle. ${ }^{5}$ (LEVINAS, 2008, p. 123)

É nesse intervalo vazio que se encontram os personagens de Sôbolos rios que vão, que surgem e desaparecem, mas estão sempre lá, não sendo possível nenhum gesto para se subtrair a esse aparecimento, mas essa aparição mesmo não podendo jamais terminar. A loira tenista, um médico identificado como um "pingo no sapato", dona Irene e sua harpa, a avó e suas frases feitas, o avô a ler o jornal, o pai a molestar a empregada, o Virgílio a conduzir sua carroça, o senhor Hélio, amigo do avô, o colega gordo que lembrava catorze nomes de rio e ele nenhum. Os seres emergem e submergem, angústia que se prolonga, como o pavor de ser enterrado vivo num ambíguo partir: "eu nesta cama com a mesma fúria de partir e incapaz de partir" (ANTUNES, 2010, p. 178), como se a morte não fosse jamais bastante morte, como se paralelamente à duração dos vivos corresse eternamente a duração do intervalo - l'entretemps.

Esse mourir a que se refere Levinas ressoa o estar a morrer blanchotiano, o espaço da outra morte, "non pas mort de cette tranquille mort du monde qui est repos, silence et fin, mais de cette autre mort qui est mort sans fin, épreuve de l'absence de fin”' (BLANCHOT, 1999, p. 227). A morte não é possível. A única possibilidade é sua impossibilidade, isto é, estar a morrer sempre na literatura, sem chegar ao termo.

Assim, temos um doente de câncer que está a morrer todo o tempo e não morre como ser de escritura, uma vez que o senhor Antunes termina o relato como Antoninho na infância, a ouvir o canto da mãe, "sobre os rios a caminho da foz" (ANTUNES, 2010, p. 199), sempre a caminho da foz, assim como as andorinhas jamais morrem, assim como a escrita nunca nasce e nem morre, assim como ele tropeça "carruagens adiante" 
do comboio que vai em direção à nascente, "a escapar do que levo comigo" (ANTUNES, 2010, p. 48), ou seja, a fugir do câncer na direção da serra, "que é da certeza de não morrer" (ANTUNES, 2010, p. 48). Como a pontuação de Lobo Antunes não é utilizada convencionalmente, a expressão que fala da incerteza da morte, ou da certeza da não-morte, tanto pode ser uma indagação, uma busca, quanto uma afirmação, como se não morrer equivalesse a uma viagem em sentido contrário. Isso nos faz pensar no sentido da escritura, tanto em termos de compreensão, de significação, quanto na acepção de orientação: que significa essa narrativa, para onde se dirige essa escritura? Em Lobo Antunes, essas perguntas não encontram respostas, ou pelo menos as mesmas respostas que se encontram em narrativas convencionais. Como não faz sentido encontrar um sentido, a narrativa fica, como fica o personagem que se recusa a morrer: "mas não faz sentido eu morrer e por não fazer sentido fico" (ANTUNES, 2010, p. 53). Da mesma forma, "os nomes dos rios se esvaziaram de sentido" (ANTUNES, 2010, p. 133), para que servem as palavras que designam os seres, principalmente seres fluidos, cuja sina é correr e correr sem que se lhes possa atribuir um sentido.

Atribuir um sentido, não obstante, parece ser a tarefa de quem fala da literatura. Afinal, é possível falar de literatura na leitura das imagens, mas sem imaginar os sentidos? No pequeno ensaio "Defesa de Kafka contra seus intérpretes”, Giorgio Agamben (1999, p. 135-136) diz que o que garante o inexplicável são as explicações que se fazem dele. Qualquer outra atitude - incluindo o silêncio - faz abalar o inexplicável, o qual se mantém firme na multiplicidade de sentidos que se lhe atribuem. Assim é a obra de Kafka, assim é a escritura de Machado de Assis, assim são os romances de Lobo Antunes.

No ensaio "La lecture de Kafka", Blanchot (2003, p. 9-19) menciona uma série de exegeses sobre a obra de Kafka e afirma que ela é um "désastre absolu", uma escrita obscura que não pode conduzir a nenhuma conclusão. Para Blanchot, é vão o movimento de buscar uma verdade extraliterária que jogue alguma luz sobre o texto kafkiano, criando narrativas sobre a narrativa, estabelecendo uma alegoria. A leitura de Kafka provoca um desconforto que acarreta interpretações muitas vezes opostas e excludentes dos comentaristas, em busca de soluções que parecem não existir. Ele menciona então sucintamente algumas observações levantadas por críticos como Claude-Edmonde Magny, Klossowski, Starobinski, e comenta os comentários: "Ces textes reflètent la malaise d'une lecture qui cherche à conserver lénigme et la solution, le malentendu et l'expression de ce malentendu, la possibilité de lire dans l'impossibilité d'intepreter cette lecture"7 (BLANCHOT, 2003, p. 10). Tentar desvendar o sentido dela é traí-la, o que Sartre não admite.

O sentido das palavras, a estabilidade dos signos são continuamente ameaçados no texto literário, no texto poético, no texto de Lobo Antunes. Em Sôbolos rios que vão, ocorre uma curiosa imagem da ausência do gato que leva a uma reflexão sobre a palavra no texto literário, envolven- 
do dois gigantes do pensamento, Jean-Paul Sartre e Maurice Blanchot. Em meio às suas memórias e esquecimentos confusos e entrelaçados, o personagem do romance de Lobo Antunes menciona um gato existente e não-existente, "um gato que era e não era" (ANTUNES, 2010, p. 82), "para quê inventar gatos se nos desprezam sempre" (ANTUNES, 2010, p. 116), "não existem gatos convençam-se" (ANTUNES, 2010, p. 116), gatos escriturais a lembrarem a flor de Mallarmé, a ausente de todos os buquês, os ausentes de todos os telhados.

A relação dos gatos com o texto literário que vamos buscar aqui remonta a 1947, quando Sartre publicou o livro Qu'est-ce que la littérature, em que o autor reivindicava um compromisso do romancista com seu tempo, sua sociedade: "La fonction d'un écrivain est d'appeler un chat un chat. Si les mots sont malades, cet à nous de les guérir. Au lieu de cela, beaucoup vivent de cette maladie." (SARTRE, 1967, p. 341). A frase que alude à existência do gato pretende aproximar a prosa de ficção da linguagem corrente - como Sartre a entende - em sua transparência.

Em seu texto "La littérature et le droit à la mort", Blanchot faz uma oposição vigorosa à concepção de Sartre. Ele se refere primeiramente ao processo de nomeação no âmbito da linguagem comum: "Le langage courant appelle un chat un chat, comme si le chat vivant et son nom étaient identiques, comme si le fait de le nommer ne consistait pas à retenir de lui que son absence, ce qu'il n'est pas"9 (BLANCHOT, 2003, p. 314). A nomeação "correta" das coisas reivindicada por Sartre encontra em Blanchot uma forte contestação: a palavra não permite a visão do objeto através da transparência sartreana. Para Blanchot, não há nenhuma identidade entre o ser e a palavra. O que fica é a ausência, a não-existência do objeto, que foi assassinado pela palavra para renascer como outra coisa, como ideia. E essa ideia é definitiva, segura. Reter as palavras, por conseguinte, sem permitir que elas retornem às coisas, é garantir sua saúde, para nossa tranquilidade e firmeza de propósitos.

Na linguagem literária, a palavra se comporta de maneira diferente: ela é pouca para as possibilidades que encerra. Uma vez aberto o lacre que limita os sentidos e faz compreender, abre-se o acesso a "autres noms, moins fixes, encore indécis, plus capables de se concilier avec la liberté sauvage de l'essence négative, des ensembles instables, non plus des termes, mais leur mouvement, glissement sens fin de "tournures" qui n'aboutissent nulle part”10 (BLANCHOT, 2003, p. 315). Se fosse isso apenas, a literatura já seria muito. Para Blanchot, o que faz a angústia da literatura é a busca de uma origem inexistente da palavra que se perde, a procura de um momento anterior, que não pode ser encontrado.

Contra o gato sartreano, Blanchot defende o gato ambíguo, já que a literatura é feita de ambiguidades, cujo ponto máximo é o lugar instável "où elle peut changer indifféremment, de sens et de signe"11 (BLANCHOT, 
2003, p. 329). Blanchot não deixa também escapar a atribuição, por Sartre, da pecha de doentes às palavras, e sua insinuação de que muitos escritores tiram partido dela:

Souvent, en ces jours, on parle de la maladie des mots, on s'irrite même de ceux qui en parlant, on les soupçonnes de rendre les mots malades pour pouvoir en parler. Il se peut. L'ennui, c'est que cette maladie est aussi la santé des mots. ${ }^{12}$ (BLANCHOT, 2003, p. 302)

A doença pode ser encarada como a saúde da palavra porque afinal o duplo sentido que a dilacera é o que pode levar à compreensão, ao diálogo. Chamar um gato de gato pode ser o ideal de um escritor, mas isso não significa que ele esteja a caminho da cura das palavras, porque, conforme insiste Blanchot, "le chat n'est pas un chat, et celui qui l'affirme nia rien d'autre en vue que cette hypocrite violence: Rolet est un fripon"13 (BLANCHOT, 2003, p. 302). Blanchot alude aqui a um fragmento do crítico e poeta francês Nicolas Boileau (1636-1711), contido em suas Sátiras, de 1660: "Je ne puis rien nommer si ce n'est par son nom;/ J'appelle un chat un chat, et Rolet un fripon"14. Rolet, contemporâneo de Boileau, foi um procurador do Parlamento de Paris. Sua desonestidade era proverbial, e chamar alguém de Rolet equivalia a chamá-lo de vigarista. Blanchot faz a alusão para confirmar o fato de que tentar estabelecer uma identidade perfeita entre duas palavras, ou entre uma palavra e um ser, ou é mistificação ou é hipocrisia, desfazendo, assim, a ilusão sartreana de que é possível dizer que um gato é um gato.

Pode-se afinal invocar uma assertiva óbvia em favor da compreensão: sim, mas o rio tem um sentido, sabe-se que se desloca para o mar, o personagem tem a certeza de que vai à foz, e ao chegar ao mar as possibilidades infinitas se abrem com a "barca bela que se vai deitar ao mar". Aqui, a indecidibilidade da imagem aquática se soma ao recurso intertextual, que, diga-se de passagem, tem sido pouco comum nas últimas obras de Lobo Antunes, com sua tendência ao despojamento. E essa utilização em Sôbolos rios que vão reafirma a concepção de Julia Kristeva de diálogo intertextual: "It can be at once a melancholic moment of crisis, a loss of voice and meaning, a void and displaced origin, and a rebellious conquest of a new polymorphous expression against any unproductive identity or totalitarian linearity" ${ }^{15}$ (KRISTEVA, 2011, p. 3). Ao se apropriar da barca bela da canção infantil com seus versos esquecidos, o efeito que o discurso provoca é o de um deslocamento contínuo de possibilidades, o de um curso incerto que se abre à infinitude das águas do mar. Assim, essa indeterminação de sentidos é sua grande força, sua riqueza maior, ao abrir possibilidades infinitas evocadas pelo intertexto, como um sortilégio que o texto literário coloca diante do leitor, que é forçado a se afastar de sua necessidade de completude, de totalidade, fazendo aflorar o que ela chama "fratura de subjetividade".

Falar das águas que rolam e se abrem ao infinito é falar do desconhecido, de significações múltiplas e variadas, é buscar relações entre 
interno e externo, entre vida e morte. Os versos da canção infantil aparecem no dia dois de abril: "a mãe cantava diante da máquina de costura e ele a acompanhá-la na enfermaria, recordava uns versos, não recordava outros" (ANTUNES, 2010, p. 169), e na ambiguidade de locução a barca bela da escritura, na voz do personagem e de sua mãe, desliza aos trancos em direção ao mar: "quem quer ver a barca bela e o resto dos versos perdido” (ANTUNES, 2010, p. 196). E assim como a barca bela busca seu rumo pelos meandros dos rios que vão, a escritura de Lobo Antunes tenta buscar seu sentido nos depoimentos, recordações, esquecimentos, sofrimentos das vozes que enunciam um discurso doente, que não se remedeia, que não se cura jamais porque não pode trazer o conforto do ato de compreender. $\mathrm{E}$ tanto a barca bela quanto a escritura vão dar ao mar, ao seu enorme silêncio infinito que nada esclarece.

Temos aí portanto Sôbolos rios que vão, um diário que não é diário, um texto vacilante e irresoluto como a voz narrativa anônima que parece conduzi-lo, misturada a outras vozes e outras pessoas. A escritura de Lobo Antunes, como as águas que rolam, banham o papel em que se escreve, formando-se linguagem poética na busca vã da nascente, nesse processo cuja origem e fim não podem ser acessados, a partir das imagens da água e da morte, que presidem a escritura. A água que se espalha por todos os lados, o tempo do mourir, do estar a morrer, fazem-se escritura a ameaçar os sentidos das palavras e a estabilidade dos signos em sua relação com os objetos representados, irremediavelmente ausentes de todos os buquês e de todos os telhados.

\section{REFERÊNCIAS BIBLIOGRÁFICAS}

AGAMBEN, Giorgio. Ideia da prosa. Lisboa: Cotovia, 1999.

ANTUNES, António Lobo. Sôbolos Rios Que Vão. Lisboa: Dom Quixote, 2010.

ARNAUT, Ana Paula. Sôbolos Rios Que Vão de António Lobo Antunes: quando as semelhanças não podem ser coincidências. Disponível em: http://ala.t15.org/livros/25SR_arnaut.pdf. Data de acesso: 12/04/2011.

BARROS, Manoel de. Memórias Inventadas: a infância. São Paulo: Planeta, 2003.

BARTHES, Roland. Aula. 10. ed. Trad. de Leyla Perrone-Moisés. São Paulo: Cultrix, 2002.

BLANCHOT, Maurice. La part du feu. Paris: Gallimard, 2003. .. L'espace littéraire. Paris: Gallimard, 1999.

CAMÕES, Luis de. Rimas. Texto estabelecido e prefaciado por Álvaro J. da Costa Pimpão. Coimbra: Almedina, 2005. 
COSTA, Bianca Albuquerque da. Relembrando a infância que não aconteceu: uma análise das "Memórias" de Manoel de Barros. In: MENEZES, Roberto Bezerra de (org.). A escritura à beira do desastre. Fortaleza: Expressão Gráfica, 2011.p. 39-52.

CROCE, Benedetto. Breviário de estética. Trad. de José Serra. Lisboa: Edições 70, 2008.

KRISTEVA, Julia. "Nous deux" or a (hi)story of intertextuality. Disponível em: wxy.seu.edu.cn/humanities/sociology/htmledit/.../20110209143 625645.pdf. Data de acesso: 10/06/2011

LEVINAS, Emmanuel. Les imprévus de l'histoire. Paris: Fata Morgana, 2008. SARTRE, Jean-Paul. Qu'est-ce que la litérature? Paris: Gallimard, 1967.

Recebido para publicação em 08/04/2013

Aprovado em 19/08/2013

\section{NOTAS}

1 Trad.: "quando ele vive a vida cotidiana, quando ele é vivo e verdadeiro, e não mais agonizante e sem verdade". Obs.: todas as traduções do francês para o português foram feitas pelo próprio autor do artigo

2 Trad.: "É preciso expressar de outra forma o que buscamos: a linguagem não se tornaria ela mesma, na literatura, toda inteira imagem, não uma linguagem que conteria imagens, ou que colocaria a realidade em figuras, mas seria sua própria imagem, imagem de linguagem, - e não uma linguagem ornada de imagens - ou ainda linguagem imaginária, linguagem que ninguém fala, ou seja, que se fala a partir de sua própria ausência, como a imagem aparece sobre a ausência da coisa, linguagem que se dirige também à sombra dos acontecimentos, não a sua realidade, e é por esse fato que as palavras que as exprimem não são signos, mas imagens, imagens de palavras e palavras em que as coisas se fazem imagens?"

3 Trad.: "A categoria da arte está ligada a essa possibilidade de os objetos "aparecerem", isto é, de se abandonarem à pura e simples semelhança por trás da qual não há nada além do ser. Só aparece aquele que se entregou à imagem, e tudo o que aparece é, nesse sentido, imaginário."

4 Trad.: "ocupam completamente o lugar do objeto para marcar sua remoção como se o objeto representado morresse, se degradasse, se desencarnasse em seu próprio reflexo"

5 Trad.: "O tempo mesmo do morrer não pode se dar a outra margem. O que esse instante tem de único e de estarrecedor deve-se ao fato de ele não poder passar. No "morrer", o horizonte do futuro é dado, mas o futuro como promessa do novo presente é recusado está-se no intervalo, para sempre intervalo."

6 Trad.: "não mais morte dessa tranquila morte do mundo que é repouso, silêncio e fim, mas dessa outra morte que é morte sem fim, prova da ausência de fim".

7 Trad.: "Esses textos refletem o mal-estar de uma leitura que procura conservar o enigma e a solução, o mal-entendido e a expressão desse mal-entendido, a possibilidade de ler na impossibilidade de interpretar essa leitura." 
8 Trad.: "A função do escritor é chamar um gato de gato. Se as palavras estão doentes, cabe a nós curá-las. Ao invés disso, muitos vivem dessa doença."

9 Trad.: "A linguagem corrente chama um gato de gato, como se o gato vivo e seu nome fossem idênticos, como se o fato de o nomear não consistisse em reter dele não mais que sua ausência, aquilo que ele não é”.

10 Trad.: "outros nomes, menos fixos, ainda indecisos, mais capazes de se conciliar com a liberdade selvagem da essência negativa, dos conjuntos instáveis, não mais dos termos, mas de seu movimento, deslizar sem fim de "construções" que não chegam a lugar nenhum".

11 Trad.: "em que ela pode mudar, indiferentemente, de sentido e de sinal".

12 Trad.: "Muitas vezes, atualmente, fala-se da doença das palavras, até nos irritamos com aqueles que falam disso, suspeitando que as tornem doentes para delas poder falar. Talvez seja. Infelizmente, essa doença é também a saúde das palavras.”

13 Trad.: "um gato não é um gato, e aquele que o afirma não tem mais nada em vista do que essa hipócrita violência: Rolet é um vigarista”.

14 Trad.: "Não posso nomear nada se não há um nome;/ chamo um gato de gato e Rolet de vigarista".

15 Trad.: "Ela pode ser ao mesmo tempo um melancólico momento de crise, a perda da voz e do significado, uma origem vazia e deslocada, e a conquista rebelde de uma nova expressão polimorfa contra qualquer identidade improdutiva ou linearidade totalitária." 